Bond University

Research Repository

\title{
Psychological distress and coping styles in teachers: A preliminary study
}

Stapleton, Peta; Garby, Sarah; Sabot, Debbie

Published in:

Australian Journal of Education

DOI:

$10.1177 / 0004944120908960$

Licence:

Other

Link to output in Bond University research repository.

Recommended citation(APA):

Stapleton, P., Garby, S., \& Sabot, D. (2020). Psychological distress and coping styles in teachers: A preliminary study. Australian Journal of Education, 64(2), 127-146. https://doi.org/10.1177/0004944120908960

\footnotetext{
General rights

Copyright and moral rights for the publications made accessible in the public portal are retained by the authors and/or other copyright owners and it is a condition of accessing publications that users recognise and abide by the legal requirements associated with these rights.
}

For more information, or if you believe that this document breaches copyright, please contact the Bond University research repository coordinator. 
Running head: PYSCHOLOGICAL DISTRESS IN TEACHERS

Psychological Distress and Coping Styles in Teachers: A preliminary study

\begin{abstract}
Teaching professionals report higher levels of work-related stress and symptoms of psychological health problems than the general population. This study examined psychological distress, coping styles, and wellbeing in 166 Australian teachers (aged $22-65$ years; $M=37.74$ years, $S D=10.84$ years). Participants completed an online survey comprising demographic items and four empirical measures (The Satisfaction with Life Scale, Subjective Happiness Scale, The Brief COPE Inventory, and The Patient Health Questionnaire). Work, workload, and finances were identified as leading sources of stress. Moreover, above-average clinical symptoms of anxiety, depression, and physical concerns were reported, and $17 \%$ of respondents met criteria for probable alcohol dependence. Results suggested that maladaptive coping strategies employed by teachers may contribute to their risk of increased psychological distress, and decreased life satisfaction and happiness. These findings indicate the need for work-based programs to enhance teachers' coping strategies in an effort to reduce psychological distress and improve overall wellbeing in teaching professionals.
\end{abstract}

Keywords: teachers, mental disorders, stress (psychology), coping, life satisfaction, wellbeing 
Psychological Distress and Coping Styles in Teachers: A preliminary study

\section{Introduction}

The adverse effects of stress on psychological wellbeing are well established in the literature (Boscarino, 2004; Schneiderman, Ironson, \& Siegel, 2005). In particular, occupational stress is negatively associated with job satisfaction, life satisfaction, and overall health (Johnson et al., 2005). The teaching profession is one group that has been identified as reporting comparatively high levels of occupational stress (Harmsen, Helms-Lorenz, Maulana, \& Van Keen, 2018; Johnson et al., 2005). Approximately 20\% to 50\% of teachers report above average work-related stress (Chaplain, 2008; Smith et al., 2000). According to a Safe Work Australia ${ }^{1}$ report, $91 \%$ of workers' compensation claims made in $2010-11$ and 2014-15 involved a mental health condition linked to work-related stress or mental stress (SWA, 2015). In this report, school teachers featured among the top three professions for compensation claims regarding work-related mental stressors. Mental stressors are considered the mechanisms of injury that describe work-related stress in claims data and can include workplace pressure and work-related harassment.

Occupational stress is moderated by a range of factors including work type, social support, and coping styles (Folkman, Lazarus, Gruen, \& Delongis, 1986; Johnson et al., 2005). Coping strategies adopted in response to prolonged stress can have significant implications for individuals' physiological and psychological wellbeing (Steptoe, 1991). Coping strategies, therefore, are considered a potential resource that can assist employees to manage their stress and achieve optimal psychological functioning (e.g. problem solving, positive reappraisal and support seeking; Johnson et al., 2005).

\footnotetext{
${ }^{1}$ Safe Work Australia (SWA) is a government statutory body responsible for policy relating to work, health, and safety issues, and workers' compensation.
} 
Positive emotions such as happiness and satisfaction with life form an important part of human functioning (Diener, 1984; Keyes, 2006). However, inherently stressful environments can adversely affect these positive wellbeing outcomes (Boujut, BruchonSchweitzer, \& Dombrowski, 2012; Cenkseven-Onder \& Sari, 2009; Hamama, Ronen, Shachar, \& Rosenbaum, 2013). Life satisfaction is considered a dynamic global assessment of an individual's life and is influenced by a multitude of factors including workplace satisfaction (Boujut et al., 2012; Yilmaz et al., 2013). Work and life satisfaction are significantly associated with happiness (Fisher, 2010; Tadi, Bakker \& Oerlemans, 2013), and in the teaching profession, lower levels of life satisfaction and happiness are linked to burnout and increased psychological distress (Hamama et al., 2013; Van Katwyk, Fox, Spector, \& Kelloway, 2000).

Given the high levels of stress identified in the teaching profession compared to the general population (Harmsen et al., 2018), examining psychological distress and coping strategies used by teachers is vital. Understanding the variables associated with teacher stress may be used to guide institutional strategies that better support teachers' psychological wellbeing (Darmody \& Smyth, 2016). Research has suggested that coping styles may provide a means by which teachers can be assisted in mitigating the impacts of work-related stress (Carver, Scheier, \& Weintraub, 1989; Parket, Martin Colmar, \& Liem, 2012). Accordingly, the current study aimed to (a) identify sources of teacher stress, (b) assess levels of psychological distress in the teaching profession, and c) examine associations between coping styles and symptoms of psychological distress, life satisfaction, and happiness in teachers. The following sections provide a summary of the literature on psychological distress, coping styles and positive outcomes, including life satisfaction and happiness in teachers.

\section{Teaching Stressors and Psychological Distress}


Various contextual factors can influence teacher stress such as increased job demands, interpersonal difficulties, and challenging student behaviour (Kokkinos, 2007; Richards, Hemphill, \& Templin, 2018; Stoeber, \& Rennert, 2008). Research suggests that teachers are more susceptible to work-related stressors and psychological distress compared to other occupations (Johnson et al., 2005; Van Droogenbroeck \& Spruty, 2015). This work stress may lead to job dissatisfaction and early attrition which present significant economic implications (Lindqvist et al., 2014; Santoro, 2018). Additionally, increased staff absenteeism, reduced morale, and poor-quality work from overly stressed teaching professionals can significantly detract from the student learning experience (Mason \& Matas, 2015).

Research suggests that high effort and low reward can elicit negative emotions and stress responses which are linked to lowered wellbeing in teachers (Van-Vegchel, Jonge, Bosma, \& Schaufeli, 2005). The Effort-Reward Imbalance model (ERI; Lehr, Hillert, \& Keller, 2009) provides a theoretical framework to help explain the impact of the work environment on wellbeing. According to the ERI model, high levels of work-related effort should be matched with high levels of rewards, such as recognition and financial reimbursement (Mark \& Smith, 2012). An imbalance between effort and reward, or lack of reciprocity, can elicit strong emotional responses, which in turn increase the risk of psychological and psychobiological health problems (Leher et al., 2009

In studies that have focused on teachers, an imbalance between efforts and rewards has been linked to affective disorders such as depression, anxiety, and somatic symptom disorders (Godin, Kittel, Coppieters, \& Siegrist, 2005; Hinz et al., 2016, Lehr et al., 2009; Siegrist \& Li, 2016). Strong associations between perceived stress, anxiety, and depressive disorders are also detailed in the literature (Bardeen, Fergus, \& Orcutt, 2013; Sanne, Mykletun, Dahl, Moen, \& Tell, 2005). Long-term exposure to stress can produce structural 
changes in the brain, which present clinical ramifications for the development of mental disorders (Bottaccioli, Bottaccioli, \& Minelli, 2018; De Alvear, Martínez, Barón, \&, Hernández-Mendo, 2010; Elbau et al., 2018; Tak \& Rosmalen, 2010). Additionally, adverse psychosocial work factors and prolonged stress are consistently linked to sleep problems and increased risk for adverse psychological consequences (Linten et al., 2015).

In Australia, the most predominant presenting mental health disorders are anxiety, depression, and substance use disorders, which affect approximately 13\%, 10\%, and 5\% of the population respectively (Australian Bureau of Statistics[ABS], 2008; ABS, 2018). Epidemiological research suggests that teachers experience mental health issues at a higher rate compared to other occupations, with work-related stress identified as the key contributor (Schonfeld, Bianchi, \& Luehring-Jones, 2017; Stansfeld, Rasul, Head, \& Singleton, 2011).

\section{Coping Style in Australian Teachers}

Coping is a combative and preventative resource that can buffer the harmful effects of stress (Carver et al., 1989). Consistent with prior research, the present study defined coping as: (1) adaptive strategies such as seeking emotional support and use of positive reframing, planning, humour, and religion; and (2) maladaptive styles involving self-distraction, denial, substance abuse, behavioural disengagement, and self-blame (Glass, Flory, Hankin, Kloos, \& Turecki, 2009). Research indicates that adaptive coping in teachers broadly contributes to increased resilience, leading to higher levels of wellbeing and happiness (Campbell-Sills, Cohan, \& Stein, 2006; Martin \& Marsh, 2008). For example, self-control, defined as the ability to refrain from employing negative actions that may exacerbate stress, appears to buffer the adverse effects of negative emotions (Brown, Westbrook, \& Challagalla, 2005).

In contrast, maladaptive coping is associated with physical health problems, emotional exhaustion, decreased job satisfaction, reduced wellbeing, and high levels of psychological distress such as depression and anxiety (Belloch, \& Garcia-Soriano, 2007; 
Harmsen et al., 2018; Johnson et al., 2005; Morrillio et al., 2007; Skaalvik \& Skaalvik, 2016; Thompson et al., 2010). Substance abuse is widely recognised in the literature as one maladaptive coping strategy to deal with stress (Pence, Thielman, Whetten, Ostermann, Kumar, \& Mugavero, 2008) and appears to affect many professions, including teachers. A study of 500 American teachers found that teachers reported a higher lifetime prevalence rate of alcohol consumption when compared to the general population (Watts \& Short, 1990). Similarly, Babalola, Ighoroje, Awangansi, and Ayilara (2017) found the prevalence of alcohol use among a sample of Nigerian teachers was two to three times higher than the epidemiology rates of the general population.

\section{Life Satisfaction and Happiness in Australian Teachers}

Previous examinations of prolonged stress, coping, life satisfaction, and happiness in the teaching profession have identified negative associations between maladaptive coping strategies, life satisfaction, and levels of happiness (Dubey \& Agarwa, 2007; Loukzadeh \& Bafrooi, 2013; Van Katwyk et al., 2000). As maladaptive coping increases, satisfaction with life appears to decrease. In an examination of burnout and quality of life in 161 teachers, maladaptive coping predicted low levels of subjective wellbeing and life satisfaction, and high levels of negative affect (Cenkseven-Onder \& Sari, 2009). Conversely, teachers who adopt more adaptive coping styles (e.g., drawing on social support and using self-control) show increased positive affect (Hamama et al., 2013). While adaptive coping appears to buffer the effects of negative emotions, maladaptive coping appears to amplify negative emotions in response to prolonged stress (Brown et al., 2005). However, little research has considered adaptive coping and maladaptive coping and their relationship with psychological distress, life satisfaction, and subjective happiness in Australian teachers. The current study aimed to address this gap. 


\section{The Present Study}

This study sought to investigate stress and psychological distress in Australian teachers and the relationships between coping styles and negative (psychological distress) and positive outcomes (life satisfaction, happiness). It was hypothesised that:

1. The most stressful life factor identified by participants would be an issue relating to teaching work in general.

2. Levels of psychological distress, assessed as symptoms of depression, anxiety, physical concerns and alcohol use, would be higher in the sample of teachers than the Australian population average.

3. (a) Adaptive coping would negatively relate to psychological distress, and (b) Maladaptive coping would positively relate to psychological distress after controlling for adaptive coping.

4. (a) Adaptive coping would positively relate to life satisfaction and happiness levels, and (b) Maladaptive coping would negatively relate to life satisfaction and happiness levels after controlling for adaptive coping.

\section{Method}

\section{Participants and Procedure}

The achieved convenience sample consisted of 166 participants (aged 22 - 65 years; $M=37.74$ years, $S D=10.84$ years), comprising 147 females $(88.6 \%), 18$ males $(10.8 \%)$, and 1 unspecified (0.6\%). Participant demographics are displayed in Table 1. Participants were recruited via Facebook online teaching forums and snowballing techniques (i.e., teachers emailed the online survey to colleagues). Inclusion criteria included teachers currently employed in the Australian education system. Prior to data collection, ethical approval was gained from the university's Human Research Ethics Committee. An online link invited 
participants to complete an anonymous survey about their health, wellbeing, and teaching practices. Participants were advised that their withdrawal was possible at any time. Informed consent was signified electronically by clicking "Yes" prior to survey commencement.

Table 1

Demographic Characteristics of Participants

\begin{tabular}{llcc}
\hline Variable & $N$ & $\begin{array}{c}\text { Total Sample } \\
(\%)^{*}\end{array}$ \\
\hline Gender & Female & 147 & 74 \\
& Male & 18 & 9 \\
& Unspecified & 1 & 0.5
\end{tabular}

Age

$\begin{array}{lcc}\leq 25 \text { years } & 19 & 11 \\ 26 \text { to } 30 \text { years } & 36 & 22 \\ 31 \text { to } 40 \text { years } & 51 & 31 \\ 41 \text { to } 50 \text { years } & 31 & 19 \\ 51 \text { to } 60 \text { years } & 27 & 16 \\ \geq 61 \text { years } & 2 & 1\end{array}$

Highest Level of

Education

$\begin{array}{lcc}\text { High School } & 1 & 0.5 \\ \text { Bachelor's } & 120 & 61 \\ \begin{array}{l}\text { Degree } \\ \text { Master's }\end{array} & 28 & 14 \\ \begin{array}{l}\text { Degree } \\ \text { Doctoral }\end{array} & 1 & 0.5 \\ \begin{array}{l}\text { Degree } \\ \text { Vocational } \\ \text { Degree }\end{array} & 32 & 16 \\ \text { Other } & 16 & 8\end{array}$

Years Teaching

$\begin{array}{lcc}1 \text { to } 5 & 60 & 36 \\ 6 \text { to } 10 & 37 & 22 \\ 11 \text { to } 15 & 24 & 14 \\ 16 \text { to } 20 & 17 & 10 \\ 21 \text { to } 25 & 13 & 8 \\ 26 \text { to } 30 & 5 & 3 \\ 31 \text { to } 35 & 8 & 5 \\ 36 \text { to } 40 & 2 & 1\end{array}$

Employment Status

Full-Time 


\begin{tabular}{llcc}
\hline Variable & & $N$ & $\begin{array}{c}\text { Total Sample } \\
(\%)^{*}\end{array}$ \\
\hline & Casual & 3 & 1 \\
& Contract & 8 & 4 \\
& Relief Teaching & 8 & 4 \\
& Other & 10 & 5 \\
Employment System & & 31 & 16 \\
& Private & 110 & 56 \\
& Government & 16 & 8 \\
Teaching Year Level & Independent & 7 & 3 \\
& Catholic & & \\
& Preschool & 15 & 19 \\
& Primary & 32 & 45 \\
& Secondary & 75 & 15 \\
& Tertiary & 25 & 11 \\
& Special & 19 & \\
& Education & & \\
& & &
\end{tabular}

*Percentages have been rounded and may not total to $100 \%$

\section{Materials and Measures}

The online survey comprised demographic items, four empirical measures (see section below), and a single qualitative question to evaluate perceived sources of stress ("What is the most stressful thing in your life right now?").

The Patient Health Questionnaire (PHQ; Spitzer, Kroenke, \& Williams, 1999).

The PHQ is a self-report questionnaire commonly used in research to screen for clinical disorders that consists of five modules (Spitzer et al., 1999). In the current study, four PHQ modules were used to assess clinical symptoms of depression, anxiety, somatoform disorders, and alcohol use, respectively.

Depression. The PHQ-9 required participants to rate the extent that nine items relating to symptoms of depression (e.g., "Feeling down, depressed, or hopeless") had bothered them over the past two-weeks using a 4-point Likert scale $(0=$ Not at All to $3=$ Nearly Every Day). Item scores were summed to produce a total score, ranging from five (mild depression symptoms) to 20 (symptoms of severe depression). The PHQ-9 has strong convergent validity, with strong correlations with known measures of depression (e.g., Beck 
Depression Inventory; $r=.73$; Martin, Rief, Klaibergm, \& Braehler, 2006). The scale had excellent internal consistency $(\alpha=.91)$ in the current sample.

Anxiety. The GAD-7 is commonly employed as a screening and monitoring tool for generalised anxiety disorder (GAD) symptom severity. Participants rated the extent to which they had been bothered by each statement (e.g., "Becoming easily annoyed or irritated") in the past four weeks on a 3-point Likert scale $(0=$ Not At All, to $2=$ More Than Half The Days). Items score were summed to produce total scores, with total scores of five, 10 , and 15 , representing mild, moderate, and severe anxiety symptoms respectively. The GAD-7 has strong test-retest reliability $(r=.84)$ and excellent reported internal consistency $(\alpha=.92$; Kroenke et al., 2010). The scale had an adequate level of internal consistency of .76 in the current sample.

Somatic (physical) symptoms. The 13-item PHQ-S was used to assess levels of somatic symptoms using a 3-point Likert scale. Participants rated the extent they were bothered by physical symptoms (e.g., "Pain in your arms, legs, or joints") over a four-week period, ranging from $0=$ Not Bothered to $3=$ Bothered $A$ Lot. Total scores range between zero and 26, with scores representing levels of somatic symptoms (i.e., 5-9 low, 10-14 medium, and 15+ high; Spitzer et al., 1999). The PHQ-S has good reported sensitivity, specificity, and internal consistency ( $\alpha=.87$; Kroneke et al., 2010), presenting a good alpha of .80 in the current sample.

Alcohol abuse. Five statements that correspond to the DSM-5's (APA, 2013) criteria for alcohol abuse and dependence were used to assess the negative consequences associated with drinking and abilities to control alcohol intake. An example item is "You had a problem getting along with other people while you were drinking". Responses were dichotomous (Yes/No). For diagnostic purposes, a "Yes" response to one or more items suggested probable alcohol abuse or dependence (Spitzer et al., 1999). This module has good 
sensitivity $(r=.62)$ and specificity $(r=.95)$ in the identification of alcohol use disorders in general populations (Diez-Quevedo, Rangil, Sanchez-Planell, Kroenke, \& Spitzer, 2001). In the current study, the scale presented an alpha of .57, which is considered adequate for applied research $(\alpha<.7$; Nunnally, 1967).

The Satisfaction with Life Scale (SWLS; Diener, Emmons, Larsen, \& Griffin, 1985)

The SWLS provided a global judgment of life satisfaction. Participants rated their agreement or disagreement with five statements, ranging from $1=$ Strongly Disagree, to $7=$ Strongly Agree (e.g., "In most ways my life is close to my ideal"). Item scores were summed to compute a total score. Higher total scores indicated higher overall satisfaction with life. The SWLS is a reliable measure of life satisfaction (e.g., $\alpha=.83$; Pavot \& Diener, 2009), with an excellent alpha of .93 in the current sample.

Subjective Happiness Scale (SHS; Lyubomirsky \& Lepper, 1999)

The SHS provided a measure of participants' subjective happiness. Participants rated four items using a 7-point Likert scale by considering their happiness relative to their peers and the extent to which each item characterised them. A sample statement is "I consider myself as $1=$ Not a Very Happy Person or $7=A$ Very Happy Person". Item scores were summed to produce total scores, with higher scores reflecting greater happiness. The SHS has excellent convergent validity, correlating with other established measures of happiness $(r=$ .62), and demonstrates excellent internal consistency $(\alpha=.90$; Lyubomirsky \& Lepper, 1999), with Cronbach's alpha of .89 in the current sample.

The Brief COPE Inventory (BCI; Carver, 1997)

The BCI was used to assess individual coping style in response to various stressors. Participants rated 28 items on a 4-point Likert scale (1 = I Haven't Been Doing This At All to 4 = I've Been Doing This A Lot). The 14 subscales of the BCI represent two different types of coping strategies: adaptive coping (i.e., emotional support, active coping, acceptance, 
instrumental support, positive reframing, planning, humour, and religion) and maladaptive coping (i.e., self-distraction, denial, substance abuse, behavioural disengagement, venting, and self-blame). Sample items from the adaptive coping include "I've been taking action to try to make the situation better" and "I've been getting help and advice from other people". Maladaptive items include "I've been turning to work or other activities to take my mind off things (self-distraction)" and "I've been using alcohol or other drugs to make myself feel better (substance abuse)". Total scores were computed as the sum of factor items, with higher scores indicating higher levels of adaptive or maladaptive coping (Glass et al., 2009). The BCI has strong convergent validity, correlating with other established measures of coping ( $r$ $=.71$; Carver, 1997). The scale presented good internal consistency in the current sample, with .85 and .77 for adaptive coping and maladaptive coping respectively.

The final sample of 166 respondents exceeded the minimum size determined by a priori power analysis ( $\mathrm{G}^{*}$ Power 3.10; Faul, Erdfelder, Lang, \& Buchner, 2007) to detect a medium-sized effect $(\alpha=.05, \beta=.20)$ (Tabachnick \& Fidell, 2013). Prior to the regression analyses, a preliminary analysis was conducted to assess for violations of assumptions. Upon inspection of the data, all assumptions of hierarchical multiple regression were met. Qualitative data collected from the single open-ended question was transferred to QSR International NVivo 12 (NVivo), a qualitative software data analysis tool for thematic analysis using a method of inductive reasoning (Schulz, 2012). Quantitative data was imported to SPSS for analysis.

\section{Results}

Inductively Developed Thematic Categories

To explore the factors influencing teachers' levels of stress, participants were asked a single open-ended question to examine what they considered to be most stressful in their 
lives. Codes and themes derived from participant responses to the single open-ended qualitative question ("What is the most stressful thing in your life right now?") guided analysis priorities (Schulz, 2012). Text search usage and word frequency analyses were conducted to examine the frequency of emergent themes. Results are graphically displayed in a word cloud (see Figure 1). The word cloud displays up to 100 words from the data, with more frequently occurring words presented in larger fonts. Three central themes emerged: work, workload, and finances.

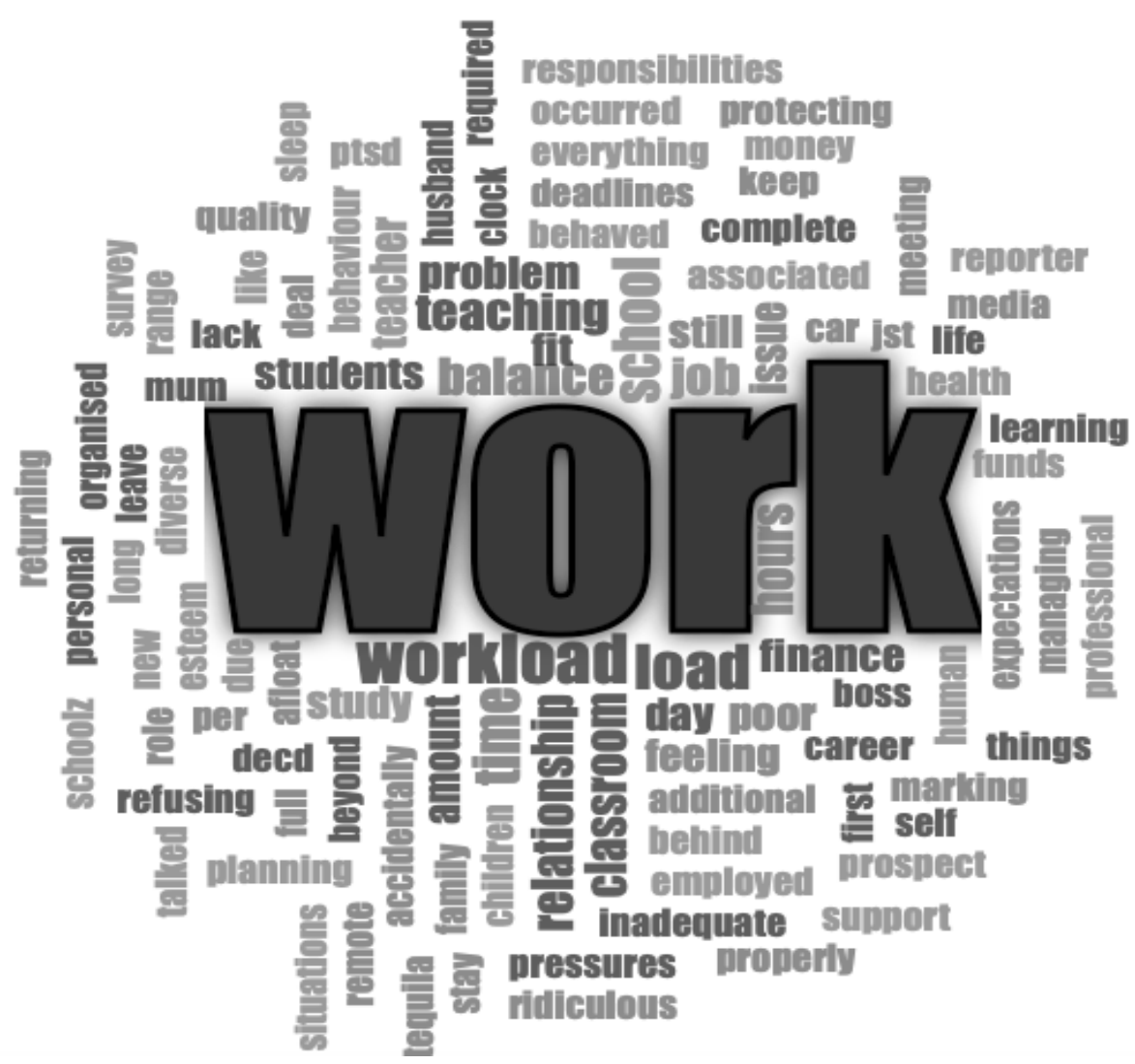

Figure 1: Sources of stress identified by participants $(N=166)$

The resulting coded themes, their frequency, and a sample response of each theme are presented in Table 2. As expected, the sample identified work as the most stressful thing in their lives. 
Table 2

Inductively Developed Thematic Categories

\begin{tabular}{lccl}
\hline Thematic Category & Frequency & Total Sample (\%)* & Example Responses \\
\hline Work & 57 & 34 & $\begin{array}{l}\text { "Work" } \\
\text { "Teaching and it's } \\
\text { unrealistic expectations" }\end{array}$ \\
Workload & 21 & 13 & $\begin{array}{l}\text { "My workload" } \\
\text { "The amount of work I } \\
\text { have to do to do my job } \\
\text { properly" }\end{array}$ \\
Finances & 16 & $\begin{array}{l}\text { "Money" } \\
\text { "Future finances" }\end{array}$ \\
Relationships & 10 & $\begin{array}{l}\text { "My children" } \\
\text { "My husband" }\end{array}$ \\
Health & 14 & 7 & $\begin{array}{l}\text { "Mental health" } \\
\text { "Infertility" }\end{array}$ \\
\hline
\end{tabular}

*Percentages have been rounded and may not total to $100 \%$

Main analysis

Means and standard deviations for the PHQ subscales were calculated to establish a measure of psychological distress in the five target areas. Based on recommended cut-off scores (Spitzer et al., 1999), approximately $18 \%$ of respondents scored in the moderately severe to severe depressive symptom range, $62 \%$ met criteria for moderate to severe anxiety, $56 \%$ met criteria for medium to high somatic severity, and $17 \%$ screened positive for possible alcohol abuse or dependence. As expected, the majority of bivariate correlations between key study variables were significant (see Table 3).

Table 3

Pearson Correlation for Main Study's Variables

\begin{tabular}{lccccc}
\hline Variable & 1. & 2. & 3. & 4. & 5. \\
\hline 1. Life Satisfaction & - & $.60^{* *}$ & $-.51^{* *}$ & .02 & $-.37 * *$ \\
\hline
\end{tabular}




\begin{tabular}{llrr}
\hline 2. Happiness & $-.53^{* *}$ & .03 & $-.50^{* *}$ \\
3. Psychological Distress & - & $.26 * *$ & $.66^{* *}$ \\
4. Adaptive Coping & & - & $.50^{* *}$ \\
5. Maladaptive Coping & & & - \\
\hline
\end{tabular}

$* p<.05 ; * * p<.001$.

A hierarchical multiple regression (HMR) was conducted to test the hypotheses that adaptive coping would be negatively associated with psychological distress while maladaptive coping behaviours would positively relate to psychological distress. At Step 1, adaptive coping accounted for $7.2 \%$ of the variance in psychological distress, $R^{2}=.07, F(1$, $164)=12.76, p<.001$, suggesting that as adaptive coping increased, psychological distress also increased $(\beta=.27 p<.001)$. At Step 2 , after controlling for adaptive coping effects, maladaptive coping accounted for an additional $38 \%$ of the variance in mental health outcomes, $\Delta F(1,163)=112.41, p<.001$. This indicated that as maladaptive coping increased psychological distress also increased $(\beta=.71, p<.001)$. Results are displayed in Table 4. Overall, the model accounted for a significant proportion of the variance in psychological distress, $F(2,163)=66.92, p<.001$.

Table 4

Hierarchical Multiple Regression Analysis - Psychological Distress Outcomes and Coping Styles.

\begin{tabular}{lccccc}
\hline Predictor & B & $\beta$ & $\mathrm{R}^{2}$ & $\Delta R^{2^{*}}$ \\
\hline Step 1 & & & & & \\
& Constant & $5.3^{* * *}$ & & & \\
& Adaptive Coping & $.44^{* * *}$ & .27 & .07 & .07 \\
& & & & & \\
\hline
\end{tabular}


Step 2

$\begin{array}{lllll}\text { Constant } & -11.6^{* *} & & & \\ \text { Adaptive Coping } & -.15 & -.09 & & \\ & & & & \\ \text { Maladaptive } & 1.7^{* * *} & .71 & .45 & .38^{* * *} \\ \text { Coping } & & & & \end{array}$

Note. $* p<.05 . * * p<.01, * * * p<.001 *$ on $\Delta R^{2}$ denotes the significance of the model and the raw value $\mathrm{R}$

A second HMR was conducted to test the hypothesis that adaptive coping would positively relate to life satisfaction and maladaptive coping would negatively relate to life satisfaction. Results at Step 1 suggested that adaptive coping was not associated with life satisfaction, $F(1,164)=0.09, p=.772$. At Step 2, after controlling for adaptive coping, maladaptive coping accounted for $20.5 \%$ of the variance in satisfaction with life, $\Delta F(1,163)$ $=42.08, p<.001$. This result indicated that higher levels of maladaptive coping were related to lower levels of life satisfaction $(\beta=-.53, p<.001)$. Overall, the model was significant, $F$ $(2,163)=21.09, p<.001($ see Table 5$)$.

Table 5

Hierarchical Multiple Regression Analysis -Life Satisfaction Outcomes from Coping Styles.

$\begin{array}{lllll}\text { Predictor } & \mathrm{B} & \beta & \mathrm{R}^{2} & \Delta R^{2 *}\end{array}$
Step 1

Constant

Adaptive Coping
$22.5^{* * *}$

.02
.001

.001 
Step 2

$\begin{array}{lll}\text { Constant } & 29.0 * * * \\ & & \\ \text { Adaptive Coping } & .25 * * * & .28\end{array}$

$\begin{array}{lllll}\text { Maladaptive Coping } & -.66 * * * & -.53 & .20 & .20 * * *\end{array}$

Note. $* p<.05 . * * p<.01, * * * p<.001 *$ on $\Delta R^{2}$ denotes the significance of the model and the raw value $\mathrm{R}$

A final HMR was performed to test the hypothesis that adaptive coping would relate positively to subjective happiness while maladaptive coping would relate negatively to subjective happiness. At Step 1, adaptive coping was not significantly associated to subjective happiness, $F(1,164)=0.15 p=.703$. At Step 2, after controlling for the effects of adaptive coping, maladaptive coping accounted for $36.8 \%$ of the variance in subjective happiness, $\Delta F(1,163)=95.01, p<.001$. This indicated that as maladaptive coping increased, subjective happiness scores decreased $(\beta=-.70, p<.001)$. Overall, the model was significant, $F(2,163)=47.66, p<.001($ see Table 6$)$.

Table 6

Hierarchical Multiple Regression Analysis - Subjective Happiness Outcomes from Coping Styles.

\begin{tabular}{lllll}
\hline Predictor & $\mathrm{B}$ & $\beta$ & $\mathrm{R}^{2}$ & $\Delta R^{2 *}$ \\
\hline
\end{tabular}

Step 1

Constant

$18.7 * * *$

Adaptive Coping

.02

.03

.001

.001

Step 2 


\begin{tabular}{lllll}
\hline Adaptive Coping & $.25^{* * *}$ & .38 & & \\
& & & & \\
Maladaptive Coping & $-.67 * * *$ & -.70 & .411 & $.36^{* * *}$
\end{tabular}

Note. $* p<.05 . * * p<.01, * * * p<.001 *$ on $\Delta R^{2}$ denotes the significance of the model and the raw value $\mathrm{R}$

\section{Discussion}

This study aimed to provide a current view of teacher psychological wellbeing through an examination of perceived stress and symptoms of mental health in an Australian teaching sample. The study also sought to identify whether adaptive and maladaptive coping strategies related to psychological distress, life satisfaction, and subjective happiness. Using a qualitative methodology, the two main sources of stress identified by participants were work and workload, as hypothesised. This result was consistent with prior research (Johnson et al., 2005; Smith et al., 2000; Van Droogenbroeck \& Spruty, 2015). Finances were identified as a third major source of stress. These qualitative results are in line with the Effort-Reward Imbalance (ERI) theory (Lehr et al., 2009) and prior research, which suggests that an increase in occupational stress arises from a lack of reciprocity between effort and reward (e.g., financial reimbursement; Bellingrath, Weigl, \& Kudielka; 2009; Zurlo et al. 2010).

Current results supported the second hypothesis; symptoms of psychological disorders were higher in the current sample than those previously reported in the general population. Current lifetime prevalence rates indicate that in the Australian population, approximately $10 \%$ experience depression, $13 \%$ experience anxiety, $7 \%$ are diagnosed with somatic symptom disorder; and 5\% are diagnosed with substance use disorders (ABS 2008; ABS; 2018; APA, 2013). Based on the PHQ’s (Spitzer et al., 1999) recommended cut-off scores for provisional diagnosis of mental disorders, the following percentages of the current teacher sample met clinical criteria: approximately $18 \%$ for moderately severe to severe depression, 
$20 \%$ for severe anxiety, and $25 \%$ for severe somatoform disorder. These findings are in line with prior research that has identified high psychological distress in teachers. In a study of 2,128 teachers, $16-18 \%$ of primary, secondary, and tertiary teachers experienced significant psychological distress (Finlay-Jones, 1986). Likewise, in a study of 574 Western Australian secondary teachers (mean teaching experience of 9.4 years, $\mathrm{SD}=4.4$ ), $45 \%$ had medium or high scores on Goldberg's (1972) General Health Questionnaire (Tuettemann \& Punch, 1992). The authors noted that the levels of psychological distress found in their teaching sample were twice that of the general population.

As stress has been considered a catalyst for the onset and progression of mental disorders, stress inherent in the teaching profession may place vulnerable individuals at higher risk for the development of mental health disorders (Esch, Stefano, Fricchione, \& Benson, 2002). However, it is important to note that the direction of causality of clinical symptoms and stress cannot be determined by the present study design. It may be that individuals' pre-existing vulnerabilities to mental health issues are exacerbated in their professional role. Several clinical intervention studies designed to improve coping skills have contributed empirical support for the need to improve mental health outcomes in the teaching profession (Cook et al., 2017; Flook, Goldberg, Pinger, Bonus, \& Davidson, 2013). For example, in a cluster randomised control study design, a mindfulness-based professional development program enhanced teachers' social and emotional competence and improved the quality of classroom interactions (Jennings et al., 2017). Future research direction may include longitudinal assessment of teaching professionals' coping styles and mental health across their careers.

The high levels of psychological distress symptoms identified in the current study are important if teachers are responsible for fostering student emotional wellbeing. If teachers' mental health outcomes are negatively impacted by work-place stress, their capacity to 
address and promote wellbeing in students may be reduced. The current Australian Curriculum stipulates that educators are required to assist students' emotional awareness and wellbeing (Australian Curriculum, Assessment, and Reporting Authority, ACARA, 2019). However, teachers who are experiencing personal difficulties may not be in a position to support this. The current findings highlight the need for increased attention on the development of work-based programs to provide teachers with support and resources to effectively address their psychological health and wellbeing needs.

Consistent with the third hypothesis, maladaptive coping strategies were related to clinical symptoms of psychological distress (depression, anxiety, somatic/physical, and alcohol use disorders). This result is in line with prior research that identified strong associations between maladaptive coping strategies and higher levels of mental health problems (Glass et al., 2009; Schnider et al., 2007; Thompson et al., 2010). Current findings suggest that maladaptive coping techniques employed by teachers to reduce stress (e.g., avoidance, behavioural disengagement, and suppression) may be associated with increased psychological distress. While some researchers have found maladaptive coping to be useful in the short-term, if the stressor is prolonged (i.e., ongoing work stress), higher levels of psychological distress can result (Kyriacou, 2001). The current findings are in line with metanalytical research, which suggests maladaptive coping is significantly correlated with psychological health outcomes, such as increased rates of depression and anxiety (Morillo et al., 2007; Thompson et al., 2010).

Contrary to prior research, the current study's results suggested that for hypothesis three adaptive coping was related to higher levels of reported psychological distress, however the association between adaptive coping and distress no longer held once maladaptive coping was added to the model. It should be noted there was a moderate positive correlation between adaptive and maladaptive coping in this sample, and this may have contributed to this 
outcome. It should also be considered whether the response scale and the wording of the items in the Brief COPE may have been contributing to a) the association between reported stress and coping style scores and b) the association between the two coping styles in the current study. The active tense of the items and response options implies current stress rather than querying a usual response, and perhaps respondents felt that they must have been currently stressed because they reported using all these coping styles. Metanalytic research also suggests that many coping strategies (adaptive and maladaptive) are associated with psychological health outcomes, and the magnitude and direction of the relationship between coping and mental health outcomes can be impacted by the duration of the stressor rather than the specific coping strategy employed (Penley, Tomaka, Wiebe, 2002). To further examine relationships between psychological distress and adaptive coping, the association could be examined in teaching samples with clinical concerns.

Finally, results did support the final hypotheses that maladaptive coping strategies would be negatively related to life satisfaction and subjective happiness. Prior research has also suggested strong links between maladaptive coping, life satisfaction, and subjective happiness (Abolghasemi \& Varanivah; Dubey \& Agarwa, 2007; Hamama et al., 2013; Lee, Kim, Wachholtz, 2016; Loukzadeh \& Bafrooi, 2013). However in the current study, adaptive coping did not explain any significant amount of variance in life satisfaction or subjective happiness, in contrast to previous findings (Páez, Seguel, \& Martínez-Sánchez, 2013). This inconsistent result warrants future research to assess coping and life satisfaction in teaching professionals.

\section{Methodological Considerations and Limitations}

The current study was not without limitations. Firstly, psychological distress can differ among teaching levels, for instance, between primary and secondary education (Eaton et al., 1990).Satisfaction with teaching is impacted by employment characteristics (i.e., 
private versus public school systems; Delprato \& Chudgar, 2018). In particular, working conditions can impact the quality of teacher instruction and student achievement (Bettini et al., 2017). Administrative support and school leadership are aspects of the teaching environment that predict increased teaching job satisfaction and lower staff attrition (Ansley et al., 2019; Bettini, Cheyney, Wang, \& Leko, 2015). It seems that effective administrative support can help to empower teaching staff to perform their roles more effectively (Bettini, Crockett, Brownell, \& Merrill, 2016). Similarly, material resources and autonomy can impact teacher attrition, particularly in the area of special education (Billingsley \& Bettini, 2019). Although acknowledged as potential mediating factors, variables relating to student behavioural difficulties, teaching environment, and remuneration were beyond the scope of the present study. The size and nature of the sample also precluded any examination of potential differences in outcomes or coping styles of different groups of teachers, such as primary and secondary teachers. Future research may benefit from an examination of how other characteristics of teachers may relate to their experiences of stress, psychological distress and use of different coping styles.

A second limitation involves the self-selection of the convenience sample, which can lead to biased estimates (Bethlehem, 2010). Given the sample was gleaned through social media sites and snowballing methodology, there is no way to ascertain if it was truly representative of the wider school teaching community. Thirdly, there was a lack of current mental health data in which to compare respondents' levels of psychological distress with the general population. Future research may benefit by concurrently comparing mental health outcomes in teachers and community samples. Due to the cross-sectional nature of the study, conclusions regarding the direction of causality of psychological distress are also not possible. Longitudinal research may help determine the influence of stress variables on psychological distress over time in the teaching population. A final limitation of the current 
study was use of the broad qualitative question which may not have adequately captured the factors of stress encountered by teachers on a daily basis. The majority of the sample reported work to be the most stressful thing in their lives; however, the current study could have been strengthened if the reasons were predefined and then free flow text options provided. Focus group-based research may assist future assessment of teacher stress, providing an opportunity to comprehensively examine attitudes and reasons for the high levels of reported stress in the teaching profession.

Notwithstanding the limitations, current results are in line with previous findings that teachers present elevated symptoms of clinical health disorders. Consequently, this research has highlighted the need for greater professional support in the education environment aimed at addressing teacher wellbeing. Additional research is necessary to explore the relationship between coping styles and psychological outcomes, in order to inform support programs that enable teachers to build upon their coping strategies and effectively manage stressors of their profession.

\section{Conclusion}

Using a mixed-method approach, this study provided an exploration of teacher stress and wellbeing. Qualitative data analysis revealed that work, workload, and finances were identified by teachers as the most significant sources of stress, in line with the Effort-Reward Imbalance model (Leher et al., 2009). Furthermore, the prevalence of symptoms of mental health disorders (depression, anxiety, somatic symptom, and alcohol use disorders) was higher in the teaching sample than general Australian population averages. Finally, findings suggest maladaptive coping strategies used by teachers may constitute a risk factor for their evaluation of psychological distress, life satisfaction, and happiness. It is suggested that future research be directed toward interventions for teaching stress and coping strategies. 
Such programs could help reduce levels of psychological distress found in the teaching profession, with significant benefits for teachers and students alike. 


\section{References}

American Psychiatric Association. (2013). Diagnostic and statistical manual of mental disorders (5th ed.). (DSM-5). Arlington, VA: American Psychiatric Publishing

Ansley, B. M., Blinder, M., Demere, J., Varjas, K., Benson, G., \& Susan, L. (2019). School personnel and leadership collaboration model for ideal work contexts. Journal of Educational Research and Practice, 9, 189-201. doi:10.5590/JERAP.2019.09.1.14

Australian Bureau of Statistics (2008). National survey of mental health and wellbeing: Summary of results, 2007 (Publications No. 4326.0). Retrieved from http://www.abs.gov.au/ausstats/abs@.nsf/mf/4326.0

Australian Bureau of Statistics (2018). Education and work, Australia, May 2018. (Publications No. 6227.0). Retrieved from http://www.abs.gov.au/ausstats/abs@.nsf/mf/6227.0/

Australian Curriculum, Assessment, and Reporting Authority (ACARA) (2019). Senior secondary curriculum overview. Retrieved from https://www.australiancurriculum.edu.au/senior-secondary-curriculum/

Babalola, E., Ighoroje, M., Awhangansi, S., \& Ayilara, O. (2017). Psychosocial correlates of hazardous alcohol use among secondary school teachers in Southwestern Nigeria. International Journal of Clinical Psychiatry, 5, 16-23. doi:10.5923/j.ijcp.20170501.03

Bardeen, J. R., Fergus, T. A., \& Orcutt, H. K. (2013). Experiential avoidance as a moderator of the relationship between anxiety sensitivity and perceived stress. Behavior Therapy, 44, 459-469. doi:10.1016/j.beth.2013.04.001

Bellingrath, S., Weigl, T., \& Kudielka, B. M. (2009). Chronic work stress and exhaustion is associated with higher allostatic load in female school teachers: Original research report. Stress, 12, 37-48. doi:10.1080/10253890802042041 
Bethlehem, J. (2010). Selection bias in web surveys. International Statistical Review, 78, 161-188. doi:10.1111/j.1751-5823.2010.00112.x

Bettini, E., Benedict, A., Thomas, R., Kimerling, J., Choi, N., \& McLeskey, J. (2017). Cultivating a community of effective special education teachers: Local special education administrators' roles. Remedial and Special Education, 38, 111-126. Retrieved from https://doi.org/10.1177/0741932516664790

Bettini, E. A., Cheyney, K., Wang, J. \& Leko, C. (2015). Job design: An administrator's guide to supporting and retaining special educators. Intervention in School and Clinic, 50, 221-225. doi:10.1177/1053451214532346

Bettini, E., Crockett, J., Brownell, M., \& Merrill, K. (2016). Relationships between working conditions and special educators' instruction. The Journal of Special Education, 50, 178-190. Retrieved from https://doi.org/10.1177/0022466916644425

Billingsley, B., \& Bettini, E. (2019). Special education teacher attrition and retention: A review of the literature. Review of Educational Research, 89, 697-744. Retrieved from https://doi.org/10.3102/0034654319862495

Boscarino, J. A. (2004). Posttraumatic stress disorder and physical illness: Results from clinical and epidemiologic studies. Annals of the New York Academy of Sciences, 1032, 141-153. doi:10.1196/annals.1314.011

Bottaccioli, A. G., Bottaccioli, F., \& Minelli, A. (2018). Stress and the psyche-brain-immune network in psychiatric diseases based on psychoneuroendocrineimmunology: A concise review. Annals of the New York Academy of Science, 1437, 31-42.

Brown, S. P., Westbrook, R. A., \& Challagalla, G. (2005). Good cope, bad cope: Adaptive and maladaptive coping strategies following a critical negative work event. Journal of Applied Psychology, 90, 792-798. doi:10.1037/0021-9010.90.4.792 
Campbell-Sills, L., Cohan, S. L., \& Stein, M. B. (2006). Relationship of resilience to personality, coping, and psychiatric symptoms in young adults. Behaviour Research and Therapy, 44, 585-599. doi:10.1016/j.brat.2005.05.001

Carver, C. S. (1997). You want to measure coping but your protocol'too long: Consider the brief cope. International Journal of Behavioral Medicine, 4, 92. doi:10.1207/s15327558ijbm0401_6

Carver, C. S., Scheier, M. F., \& Weintraub, J. (1989). Assessing coping strategies: A theoretically based approach. Journal of Personality and Social Psychology, 56, 267283. doi:10.1037/0022-3514.56.2.267

Cenkseven-Onder, F., \& Sari, M. (2009). The quality of school life and burnout as predictors of subjective well-being among teachers. Educational Sciences: Theory and Practice, 9, 223-123. Retrieved from https://files.eric.ed.gov/fulltext/EJ858924.pdf

Chaplain, R. (2008). Stress and psychological distress among trainee secondary teachers in England. Educational Psychology, 28, 195-209. doi:10.1080/01443410701491858

Cook, C. R., Miller, F. G., Fiat, A., Renshaw, T., Frye, M., Joseph, G., \& Decano, P. (2017). Promoting secondary teachers' well-being and intentions to implement evidence-based practices: Randomized evaluation of the achiever resilience curriculum. Psychology in the Schools, 54, 13-28. doi:10.1002/pits.21980

Darmody, M., \& Smyth, E. (2016). Primary school principals' job satisfaction and occupational stress. International Journal of Educational Management, 30, 115-128. doi:10.1108/IJEM-12-2014-0162

De Alvear, R. M. B., Martínez, G. A., Barón, F. J., \& Hernández-Mendo, A. (2010). An interdisciplinary approach to teachers' voice disorders and psychosocial working conditions. Folia Phoniatrica et Logopaedica, 62, 24-34. doi:10.1159/000239060 
Delprato, M., \& Chudgar, A. (2018). Factors associated with private-public school performance: Analysis of TALIS-PISA link data. International Journal of Educational Development, 61, 155-172. doi:10.1016/j.ijedudev.2018.01.002

Deniz, M. E. (2006). The relationships among coping with stress, life satisfaction, decisionmaking styles and decision self-esteem: An investigation with Turkish university students. Social Behavior and Personality, 34, 1161-1170.

doi:10.2224/sbp.2006.34.9.1161

Diener, E., Emmons, R. A., Larsen, R. J., \& Griffin, S. (1985). The satisfaction with life scale. Journal of Personality Assessment, 49, 71-75. doi:10.1207/s15327752jpa490113

Diez-Quevedo, C., Rangil, T., Sanchez-Planell, L., Kroenke, K., \& Spitzer, R. L. (2001). Validation and utility of the patient health questionnaire in diagnosing mental disorders in 1,003 general hospital Spanish inpatients. Psychosomatic Medicine, 63, 679-686. doi:10.1097/00006842-200107000-00021

Dragano, N., Siegrist, J., Nyberg, S. T., Lunau, T., Fransson, E. I., Alfredsson, L., . . . Kivimäki, M. (2017). Effort-reward imbalance at work and incident coronary heart disease: A multi-cohort study of 90,164 individuals. Epidemiology, 28, 619-626. doi:10.1097/EDE.000000000666

Dubey, A., \& Agarwal, A. (2007). Coping strategies and life satisfaction: Chronically ill patients' perspectives. Journal of the Indian Academy of Applied Psychology, 33, 161168. Retrieved from http://medind.nic.in/jak/t07/i2/jakt07i2p161.pdf

Elbau, I. G., Brücklmeier, B., Uhr, M., Arloth, J., Czamara, D., Spoormaker, V. I., ... \& Sämann, P. G. (2018). The brain’s hemodynamic response function rapidly changes under acute psychosocial stress in association with genetic and endocrine stress response markers. Proceedings of the National Academy of Sciences, 115, E10206E10215. doi:10.1073/pnas.1804340115 
Esch, T., Stefano, G. B., Fricchione, G., \& Benson, H. (2002). The role of stress in neurodegenerative diseases and mental disorders. Neuroendocrinology Letters, 2, 199208. doi:10.11/295412

Fahlén, G., Knutsson, A., Peter, R., Åkerstedt, T., Nordin, M., Alfredsson, L., \& Westerholm, P. (2006). Effort-reward imbalance, sleep disturbances and fatigue. International Archives of Occupational and Environmental Health, 79, 371-378. doi:10.1007/s00420-005-0063-6

Faul, F., Erdfelder, E., Lang, A. G., \& Buchner, A. (2007). G* Power 3.10: A flexible statistical power analysis program for the social, behavioral, and biomedical sciences. Behavior Research Methods, 39, 175-191.

Finlay-Jones, R. (1986). Factors in the teaching environment associated with severe psychological distress among school teachers. Australian and New Zealand Journal of Psychiatry, 20(3), 304-313. doi: 10.3109/00048678609158878

Flook, L., Goldberg, S. B., Pinger, L., Bonus, K., \& Davidson, R. J. (2013). Mindfulness for teachers: A pilot study to assess effects on stress, burnout, and teaching efficacy. Mind, Brain, and Education, 7, 182-195. doi:10.1111/mbe.12026

Folkman, S., Lazarus, R. S., Gruen, R. J., \& Delongis, A. (1986). Appraisal, coping, health status, and psychological symptoms. Journal of Personality and Social Psychology, 50, 571-579. doi:10.1037/0022-3514.50.3.571

Glass, K., Flory, K., Hankin, B., Kloos, B., \& Turecki, G. (2009). Are coping strategies, social support, and hope associated with psychological distress among hurricane Katrina survivors? Journal of Social and Clinical Psychology, 28, 779-795. doi:10.1521/jscp.2009.28.6.779 
Godin, I., Kittel, F., Coppieters, Y., \& Siegrist, J. (2005). A prospective study of cumulative job stress in relation to mental health. BMC Public Health, 5, 67. doi:10.1186/1471$2458-5-67$

Goldberg, D. P. (1972). The detection of psychiatric illness by questionnaire. Maudsley Monograph No. 21. Ney York: Oxford University Press.

Hamama, L., Ronen, T., Shachar, K., \& Rosenbaum, M. (2013). Links between stress, positive and negative affect, and life satisfaction among teachers in special education schools. An Interdisciplinary Forum on Subjective Well-Being, 14, 731-751. doi:10.1007/s10902-012-9352-4

Harmsen, R., Helms-Lorenz, M., Maulana, R., \& Van Veen, K. (2018). The relationship between beginning teachers' stress causes, stress responses, teaching behaviour and attrition. Teachers and Teaching, 24, 626-643. doi:10.1080/13540602.2018.1465404

Hinz, A., Zenger, M., Brähler, E., Spitzer, S., Scheuch, K., \& Seibt, R. (2016). Effort-reward imbalance and mental health problems in 1074 German teachers, compared with those in the general population. Stress and Health, 32, 224-230.doi:10.1002/smi.2596

Jachens, L., Houdmont, J., \& Thomas, R. (2016). Effort-reward imbalance and heavy alcohol consumption among humanitarian aid workers. Journal of Studies on Alcohol and Drugs, 77, 904-913. doi:10.15288.2016.77.904

Jennings, P. A., Brown, J. L., Frank, J. L., Doyle, S., Oh, Y., Davis, R., ... \& Greenberg, M. T. (2017). Impacts of the CARE for teachers program on teachers' social and emotional competence and classroom interactions. Journal of Educational Psychology, 109, 1010-1028. doi:10.1037/edu0000187

Johnson, S., Cooper, C., Cartwright, S., Donald, I., Taylor, P., \& Millet, C. (2005). The experience of work-related stress across occupations. Journal of Managerial Psychology, 20, 178-187. doi:10.1108/02683940510579803 
Kokkinos, C. M. (2007). Job stressors, personality and burnout in primary school teachers. British Journal of Educational Psychology, 77, 229-243. doi:10.1348/000709905X90344

Kroenke, K., Spitzer, R. L., Williams, J. B. W., \& Löwe, B. (2010). The patient health questionnaire, somatic, anxiety, and depressive symptom scales: A systematic review. General Hospital Psychiatry, 32, 345-359. doi:10.1016/j.genhosppsych.2010.03.006

Kyriacou, C. (2001). Teacher stress: Directions for future research. Educational Review, 53, 27-35. doi:10.1080/00131910120033628

Lee, J., Kim, E., \& Wachholtz, A. (2016). The effect of perceived stress on life satisfaction: The mediating effect of self-efficacy. Chongsonyonhak Yongu, 23, 29. doi:10.21509/KJYS.2016.10.23.10.29

Lehr, D., Hillert, A., \& Keller, S. (2009). What can balance the effort? Associations between effort-reward imbalance, over-commitment, and affective disorders in German teachers. International Journal of Occupational and Environmental Health, 15, 374384. doi:10.1179/oeh.2009.15.4.374

Lindqvist, P., Nordänger, U. K., \& Carlsson, R. (2014). Teacher attrition the first five years A multifaceted image. Teaching and Teacher Education, 40, 94-103. doi:10.1016/j.tate.2014.02.005

Loukzadeh, Z., \& Bafrooi, B. (2013). Association of coping style and psychological wellbeing in hospital nurses. Journal of Caring Sciences, 2, 313-319. doi: $10.5681 /$ jcs.2013.037

Lyubomirsky, S., \& Lepper, H. (1999). A measure of subjective happiness: Preliminary reliability and construct validation. Social Indicators Research, 46, 137-155. Retrieved from http://sonjalyubomirsky.com/subjective-happiness-scale-shs/ 
Mark, G., \& Smith, A. P. (2012). Occupational stress, job characteristics, coping, and the mental health of nurses. British Journal of Health Psychology, 17, 505. doi:10.1111/j.2044-8287.2011.02051.x

Martin, A. J., \& Marsh, H. W. (2008). Academic buoyancy: Towards an understanding of students' everyday academic resilience. Journal of School Psychology, 46, 53-83. doi:10.1016/j.jsp.2007.01.002

Martin, A., Rief, W., Klaiberg, A., \& Braehler, E. (2006). Validity of the brief patient health questionnaire mood scale (PHQ-9) in the general population. General Hospital Psychiatry, 28, 71-77. doi:10.1016/j.genhosppsych.2005.07.003

Mason, S., \& Matas, C. P. (2015). Teacher attrition and retention research in Australia: Towards a new theoretical framework. Australian Journal of Teacher Education, 40. doi:10.14221/ajte.2015v40n11.3

Morillo, C., Belloch, A., \& Garcia-Soriano, G. (2007). Clinical obsessions in obsessivecompulsive patients and obsession-relevant intrusive thoughts in non-clinical, depressed and anxious subjects: Where are the differences? Behaviour Research and Therapy, 45, 1319-1333. doi:10.1016/j.brat.2006.11.005

Nunnally, J.C. (1967). Psychometric theory. ( $\left.3^{\text {rd }} E d\right)$. New York: McGraw-Hill.

Pavot, W., \& Diener, E. (2009). Review of the satisfaction with life scale. In assessing wellbeing (pp. 101-117). Springer, Dordrecht.

Páez, D., Seguel, A. M., \& Martínez-Sánchez, F. (2013). Incremental validity of alexithymia, emotional coping and humour style on happiness and psychological well-being. Journal of Happiness Studies, 14, 1621-1637. doi:10.1007/s10902-012-9400-0

Parker, P. D., \& Martin, A. J. (2009). Coping and buoyancy in the workplace: Understanding their effects on teachers' work-related well-being and engagement. Teaching and Teacher Education, 25, 68-75. doi:10.1016/j.tate.2008.06.009 
Penley, J., Tomaka, J., \& Wiebe, J. (2002). The association of coping to physical and psychological health outcomes: A meta-analytic review. Journal of Behavioral Medicine, 25, 551-603. doi:10.1023/A:1020641400589

Richards, K. A., Hemphill, M. A., \& Templin, T. J. (2018). Personal and contextual factors related to teachers' experience with stress and burnout. Teachers and Teaching, Theory and Practice, 24, 768-787. doi:10.1080/13540602.2018.1476337

Safe Work Australia. (2015). Work-related mental disorders profile. Retrieved from https://www.safeworkaustralia.gov.au/system/files/documents/1702/work-relatedmental-disorders-profile.pdf

Safe Work Australia. (2018). Mental health. Retrieved from https://www.safeworkaustralia.gov.au/topic/mental-health

Sanne, B., Mykletun, A., Dahl, A. A., Moen, B. E., \& Tell, G. S. (2005). Testing the job demand-control-support model with anxiety and depression as outcomes: The Hordaland health study. Occupational Medicine, 55, 463-473. doi:10.1093/occmed/kqi071

Schneiderman, N., Ironson, G., \& Siegel, S. D. (2005). Stress and health: Psychological, behavioral, and biological determinants. Annual Review of Clinical Psychology, 1, 607628. doi:10.1146/annurev.clinpsy.1.102803.144141

Schonfeld, I. S., Bianchi, R., \& Luehring-Jones, P. (2017). Consequences of job stress for the mental health of teacher. New York, NY, USA: Springer

Schulz, J. (2012). Analysing your interviews. Southampton Education School Digital Media Resources. Retrieved from https://www.youtube.com/watch?v=59GsjhPolPs

Siegrist, J., \& Li, J. (2016). Associations of extrinsic and intrinsic components of work stress with health: a systematic review of evidence on the effort-reward imbalance model. 
International Journal of Environmental Research and Public Health, 13, 432-446. doi:10.3390/ijerph13040432.

Sierra-Fonseca, J. A., \& Gosselink, K. L. (2018). Tauopathy and neurodegeneration: A role for stress. Neurobiology of Stress, 9, 105-112. doi: 10.1016/j.ynstr.2018.08.009

Skaalvik, E. M., \& Skaalvik, S. (2016). Teacher stress and teacher self-efficacy as predictors of engagement, emotional exhaustion, and motivation to leave the teaching profession. Creative Education, 7, 1785-1799. Retrieved from http://dx.doi.org/10.4236/ce.2016.713182

Smith, A., Johal, S., Wadsworth, E., Davey Smith, G., \& Peters, T. (2000). The Scale of occupational stress: The Bristol stress and health at work study. Norwich: HSE.

Spitzer, R. L., Kroenke, K., \& Williams, J. B. (1999). Validation and utility of a self-report version of PRIME-MD: the PHQ primary care study. Primary care evaluation of mental disorders. Patient health questionnaire. JAMA, 282, 1737-1744. doi:10.1001/jama.282.18.1737

Stansfeld, S., Rasul, F., Head, J., \& Singleton, N. (2011). Occupation and mental health in a national UK survey. The International Journal for Research in Social and Genetic Epidemiology and Mental Health Services, 46, 101-110. doi:10.1007/s00127-009-0173

Steptoe, A. (1991). Invited review: The links between stress and illness. Journal of Psychosomatic Research, 35, 633-644. doi:10.1016/0022-399990113-3

Stoeber, J., \& Rennert, D. (2008). Perfectionism in school teachers: Relations with stress appraisals, coping styles, and burnout. Anxiety, Stress, \& Coping, 21, 37-53. doi:10.1080/10615800701742461

Tabachnick, B. G., \& Fidell, L. S. (2013). Using multivariate statistics (6th ed.). Boston: Pearson. 
Tak, L. M., \& Rosmalen, J. G. (2010). Dysfunction of stress responsive systems as a risk factor for functional somatic syndromes. Journal of Psychosomatic Research, 68, 461468. doi:10.1016/j.jpsychores.2009.12.004

Thompson, R. J., Mata, J., Jaeggi, S. M., Buschkuehl, M., Jonides, J., \& Gotlib, I. H. (2010). Maladaptive coping, adaptive coping, and depressive symptoms: Variations across age and depressive state. Behaviour Research and Therapy, 48, 459-466.

doi:10.1016/j.brat.2010.01.007

Tuettemann, E., \& Punch, K. F. (1992). Psychological distress in secondary teachers: Research findings and their implications. Journal of Educational Administration, 30, 42. doi:10.1108/09578239210008817

Van Droogenbroeck, F., \& Spruty, B. (2015). Do teachers have worse mental health? Review of the existing comparative research and results from the Belgian health interview survey. Teaching and Teacher Education, 51, 88-100. doi:10.1016/j.tate.2015.06.006

Van Katwyk, P. T., Fox, S., Spector, P. E., \& Kelloway, E. K. (2000). Using the job-related affective well-being scale to investigate affective responses to work stressors. Journal of Occupational Health Psychology, 5, 219-230. doi:10.1037/1076-8998.5.2.219

Watts, W. D., \& Short, A. P. (1990). Teacher drug use: A response to occupational stress. Journal of Drug Education, 20, 47-65. doi: 10.2190/XWW0-7FBH-FXVB-2K3C

Zurlo, M., Pes, D., \& Siegrist, J. (2010). Validity and reliability of the effort-reward imbalance questionnaire in a sample of 673 Italian teachers. International Archives of Occupational and Environmental Health, 83, 665-674. doi:10.1007/s00420-010-0512- 